\title{
Plasma levels of catecholamines and asymmetric dimethylarginine levels as predictive values of mortality among hemodialysis patients
}

\author{
Marcin Dziedzic $^{1 *}$, Ewelina Orlowska ${ }^{2}$, Kinga Gawel $^{3}$, Magdalena Zawadzka $^{1}$, \\ Anna BednareK-SKublewsKa ${ }^{4}$, Janusz SolsKi ${ }^{1}$
}

\author{
${ }^{1}$ Department of Laboratory Diagnostics, Medical University of Lublin, Chodzki 1, 20-093 Lublin, Poland \\ ${ }^{2}$ Department of Nephrology and Hypertension, Provincial Hospital of Lublin, Poland \\ ${ }^{3}$ Department of Pharmacology and Pharmacodynamics, Medical University of Lublin, Poland \\ ${ }^{4}$ Department of Nephrology, Medical University of Lublin, Poland
}

\begin{tabular}{|c|c|}
\hline ARTICLE INFO & ABSTRACT \\
\hline $\begin{array}{l}\text { Received } 13 \text { February } 2014 \\
\text { Accepted } 06 \text { March } 2014\end{array}$ & $\begin{array}{l}\text { The aim of the study was to assess plasma concentration of catecholamines and asymmetric } \\
\text { dimethyl arginine levels and a possible relationship to predict the mortality rates among }\end{array}$ \\
\hline $\begin{array}{l}\text { Keywords: } \\
\text { catecholamines, } \\
\text { asymmetric dimethylarginine, } \\
\text { hemodialysis, } \\
\text { renal failure }\end{array}$ & $\begin{array}{l}\text { hemodialysis patients. The study population comprised } 27 \text { subjects, aged } 65-70 \text { years. Each } \\
\text { patient underwent dialysis thrice a week. Furthermore, the median duration of hemodialysis } \\
\text { was } 3.5 \text { years. Based on the conducted research, it can be concluded that the concentrations } \\
\text { of adrenaline and the level of asymmetric dimethylarginine have predictive value of mortality } \\
\text { among hemodialysis patients. Of note, lowering plasma asymmetric dimethylarginine } \\
\text { concentration may represent therapeutic target for prevention of progressive renal damage. }\end{array}$ \\
\hline
\end{tabular}

\section{INTRODUCTION}

Despite progress in medical care, there is still a problem of high mortality in patients on dialysis. The major cause of death in hemodialysis (HD) patients is cardiovascular disease. It constitutes $53 \%$ causes of death $[1,7,22,29]$. In addition to traditional risk factors for cardiovascular disease like hypertension, diabetes, lipid disorders, volume overload of the circulatory system associated not only with renal failure (RF), but also with the presence of arteriovenous anastomosis and rapid changes in blood volume during HD, chronic systemic inflammation, accumulation of uremic toxins and disorders of calcium and phosphate are responsible. Most patients starting dialysis are hypertensive, suggesting that blood pressure (BP) control is an important target to reduce cardiovascular mortality [23]. Furthermore, the increased sympathetic nerve activity at least in part can explain the raised in plasma catecholamines (CA) observed in chronic kidney diseases. The elevated levels of CA in end-stage renal disease (ESRD) patients are the results of the inhibition of nitric oxide (NO) followed by increased angiotensin II and increases in sympathetic afferent outflow from diseased kidney but also of reduced CA clearance.

\footnotetext{
Corresponding author

* e-mail: marcindziedzic@live.com

tel.: +48504 325077
}

Raised sympathetic activity and alterations in nitric oxide synthesis attributable to accumulation of the endogenous nitric oxide synthesis inhibitor asymmetric dimethyloarginine (ADMA) is now recognized as an important mechanism involved in cardiovascular complication [28]. NO is a prominent compound in the heart and its vasculature and plays an intriguing role in the physiology of this organ. In the coronary vasculature, $\mathrm{NO}$ is involved in vasodilatation, down regulation of cellular adhesion molecules, inhibition of platelet aggregation, vascular proliferation, and angiogenesis. It is very important to study the role of arginine in this type of patient, since nitric oxide synthase (NOS) activity in kidney failure is determined by arginine concentration [19], the key role of the kidney in the production of the NO precursor making renal patients prone to NO deficiency [2]. Several studies have found that the plasma levels of ADMA in healthy subjects with no apparent cardiovascular disease are related to age, BP, insulin resistance, and carotid intimamedia thickness $[18,27]$. These findings suggest that an increase in ADMA levels is a marker for arteriosclerotic changes. For this reason, ADMA levels have been used for assessing cardiovascular risk [26, 28, 31]. It is worth noting that ADMA levels are elevated in patients with early phases of renal disease, even before glomerular filtration significant reduction [11]. This suggests that only a very small fraction of circulating ADMA is excreted through urine, although it is negatively correlated with Glomerular Filtration Rate (GFR); [28, 31]. 
The aim of the study was to assess plasma concentration of CA and ADMA levels and possible relationship between them to predict the values of mortality among HD patients.

\section{METHODS}

The study population comprised 27 subjects, aged 65-70 years. Each patient underwent dialysis thrice per week. Furthermore, the median duration of HD was 3.5 years. Plasma concentration of CA were measured prior HD by high performance liquid chromatography with electrochemical detection (HPLC-ED). Plasma ADMA was measured by commercially available enzyme linked immunoassay (DLD Diagnostika GmbH, Hamburg, Germany). All statistical analyses were performed using the Statistica 10.0 software. In order to investigate the diagnostic value of ADMA and plasma CA were plotted Receiver Operating Characteristic (ROC) curve and the area under the curve (AUC) was calculated to describe the capability of the markers to discriminate between dead and live HD patients during 55 months observation. Survival curves were estimated by the Kaplan-Meier product-limit method. A P-value $<0.05$ was considered to be statistically significant.

\section{RESULTS}

The main clinical characteristics of patients included in the study are detailed in Table 1. During follow-up period (55 months), 27 patients died due to cardiovascular complication (sudden cardiac arrest and sudden cardiac death, cardiomyopathy, increased cardiac electrical instability). Mean level of ADMA was $0.59 \pm 0.44 \mu \mathrm{mol} / \mathrm{l}$, noradrenalin was $741.8 \pm 461 \mathrm{pg} / \mathrm{ml}$, adrenaline was $82.36 \pm 19.96 \mathrm{pg} / \mathrm{ml}$, dopamine was $48.94 \pm 23.8 \mathrm{pg} / \mathrm{ml}$. We demonstrated Spearman rang correlation between ADMA and CA in Table 2.

Table 1. Biochemical characteristics of patients on long-term dialysis $(\mathrm{N}=27)$

\begin{tabular}{|l|c|}
\hline \multicolumn{1}{|c|}{ Parameter } & Standard deviation \\
\hline ADMA $[\mu \mathrm{mol} / \mathrm{L}]$ & $0.59 \pm 0.44$ \\
\hline Noradrenalin $[\mathrm{pg} / \mathrm{mL}]$ & $741.8 \pm 461.0$ \\
\hline Adrenalin $[\mathrm{pg} / \mathrm{mL}]$ & $82.36 \pm 19.96$ \\
\hline Dopamine $[\mathrm{pg} / \mathrm{mL}]$ & $48.94 \pm 23.8$ \\
\hline hs-CRP $[\mathrm{mg} / \mathrm{l}]$ & $7.93 \pm 6.14$ \\
\hline Cholesterol $[\mathrm{mg} / \mathrm{dl}]$ & $181.0 \pm 45.2$ \\
\hline HDL-cholesterol $[\mathrm{mg} / \mathrm{dl}]$ & $46.1 \pm 14.4$ \\
\hline LDL-cholesterol $[\mathrm{mg} / \mathrm{dl}]$ & $103.9 \pm 38.7$ \\
\hline Triglycerides $[\mathrm{mg} / \mathrm{dl}]$ & $148.6 \pm 134.0$ \\
\hline Albumin $[\mathrm{g} / \mathrm{dl}]$ & $3.76 \pm 0.26$ \\
\hline MAP $[\mathrm{mmHg}]$ & $88.66 \pm 11.85$ \\
\hline Survival $[\mathrm{months}]$ & $42.0 \pm 3.2$ \\
Age [years ] & $65.0 \pm 13.5$ \\
\hline
\end{tabular}

Table 2. Correlations between ADMA and catecholamines among 27 deceased

\begin{tabular}{|l|c|c|c|}
\hline \multicolumn{1}{|c|}{ Correlates } & $\mathrm{N}$ & Spearman $\mathrm{R}$ & $\mathrm{P}$-value \\
\hline ADMA vs Noradrenalin & 27 & 0.41 & $0.02^{*}$ \\
\hline ADMA vs Adrenalin & 27 & 0.45 & $0.01^{*}$ \\
\hline ADMA vs Dopamine & 27 & 0.49 & $0.009^{*}$ \\
\hline ADMA vs hs-CRP & 27 & 0.4 & $0.03^{*}$ \\
\hline
\end{tabular}

$* \mathrm{P}<0.05$
There was a positive correlation between ADMA and adrenaline $(\mathrm{R}=45 ; \mathrm{P}=0.01)$; (Fig. 1$)$, dopamine $(\mathrm{R}=0.49$; $\mathrm{P}=0.009)$ and related to noradrenalin $(\mathrm{R}=0.41 ; \mathrm{P}=0.02)$ as well as $\mathrm{C}$-reactive protein $(\mathrm{CRP}) ;(\mathrm{R}=0.4 ; \mathrm{P}=0.03)$. The ROC curve for the ADMA values indicates diagnostic sensitivity and specificity of ADMA (AUC 0.58 ) positive and negative predictive values for cut-off value $0.85 \mu \mathrm{mol} / 1$ are $81.8 \%$ and $89.5 \%$, respectively. While the ROC curve for level of adrenaline (AUC 0.671) indicate positive and negative predictive values for cut-off value $26.27 \mathrm{pg} / \mathrm{ml}$ are $89.78 \%$ and $95.5 \%$ (Fig.2). Kaplan-Meier curve analyses of

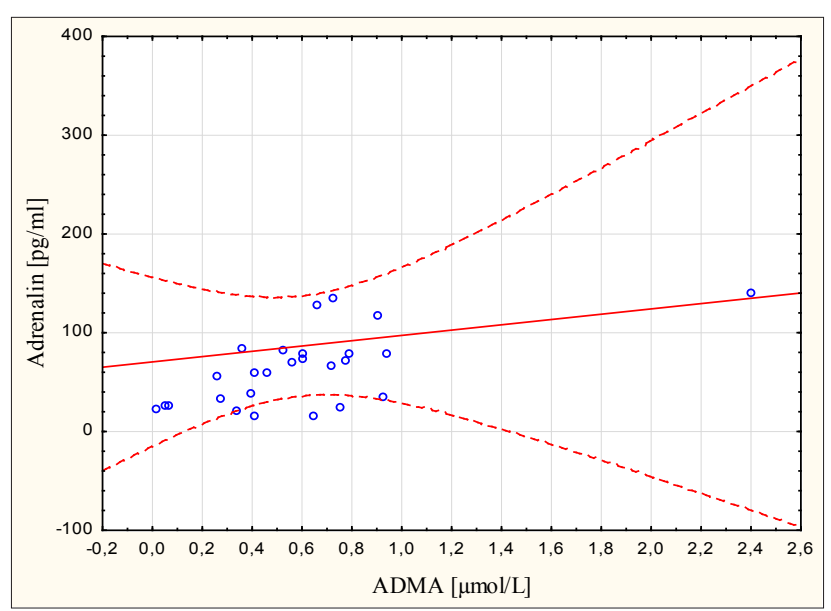

Figure 1. Correlation between the levels of adrenalin and ADMA among 27 deceased

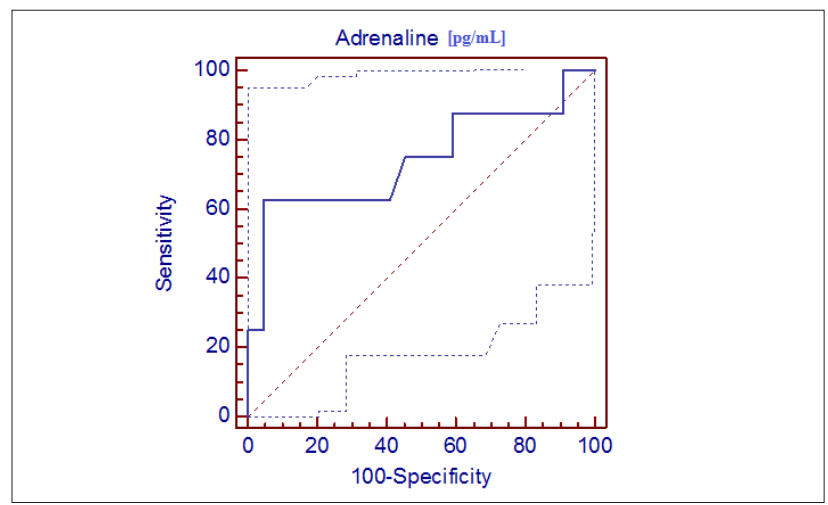

Figure 2. Receiver-operating characteristics curve for adrenaline in hemodialysis patients

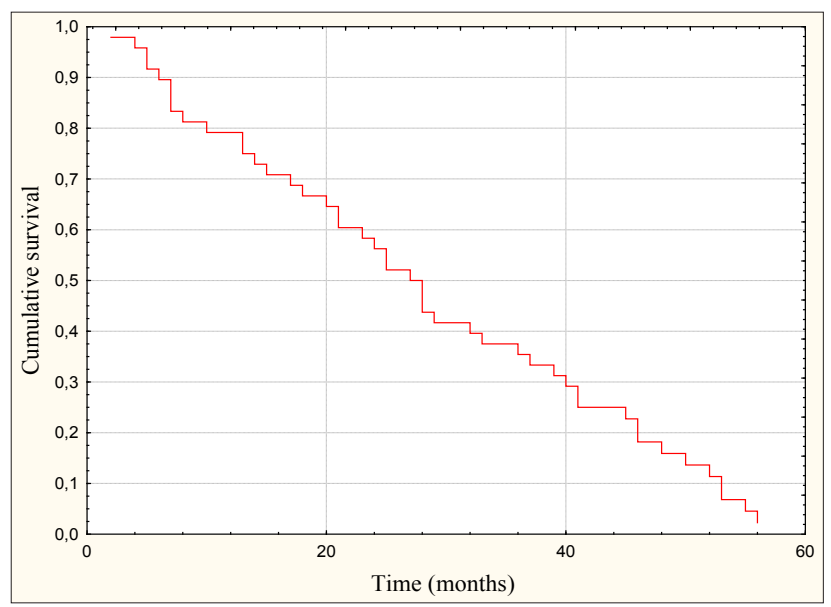

Figure 3. Kaplan-Meier survival analyses during follow-up for hemodialysis patients 
110 subjects showed that event-free survival curves among HD patients indicated $25 \%$ of the deceased in the first 13 months of HD therapy (the first 13 months of HD therapy is a critical period for the patient). Fifty percent of the dead survive longer than 55 months HD therapy $(\log \operatorname{rank}=7.21$; $\mathrm{P}=0.004)$;(Fig.3).

\section{DISCUSSION}

Approximately $50 \%$ of the deaths in patients with chronic $\mathrm{RF}$ can be attributed to cardiac events. This rate is 5-20 times higher in these patients than the one observed in the general population $[3,9,10,14]$. Regardless of the mechanism underlying their association, it seems important to study the interaction between CA and ADMA levels with respect to the high mortality and cardiovascular morbidity rates for patients with ESRD.

Of note, an analysis of interaction in predicting death and cardiovascular outcomes may provide useful clues from an understanding of these mechanisms.

In this study, the relationships between the ADMA and CA as well as CRP were examined among HD patients. It is worth noting that studies have reported a relationship between elevated ADMA and CA concentrations. There are many possible explanations for this relationship but it has still been unclear. However, our data is consistent with a recent study by Mallamaci and co-workers [16] which suggests that impairment in NO synthesis by ADMA may augment noradrenaline release. This hypothesis would be in line with the results of studies confirming that NO inhibited noradrenaline release from rat cardiac sympathetic nerve endings [24]. On the other hand, several authors have reported a direct relationship between high $\mathrm{BP}$ and ADMA levels $[8,30]$. It should, however, be taken into account that the increased sympathetic tone may lead to elevation of plasma ADMA concentrations. Therefore, it is quite possible that these two factors are likely to be involved in the same causal pathway leading to death and cardiovascular events. Another possible explanation would be that ADMA accumulation in patients with chronic RF $[12,28]$, inhibits the activity of NOS, which may explain, at least to some extent, the high BP and endothelial dysfunction seen in these patients [2]. These factors contribute to endothelial dysfunction, cardiovascular risk and the progression of renal damage.

In the present study, a correlation between ADMA and CA levels was observed in HD patients. Furthermore, we calculated diagnostic sensitivity and specificity of ADMA and CA concentration for cut-off value $26.27 \mathrm{pg} / \mathrm{ml}$, which are $89.78 \%$ and $95.5 \%$, respectively. So far, there have been very few studies on ADMA and CA levels. These results of the first studies conducted in HD were really surprising. ADMA might have functional impact on CA concentration being associated with enhanced system, generation of reactive oxygen species, as well as putatively attributable to inhibition of diethyldiaminohydrolase. This apparent discrepancy may reflect differences in the acute and chronic effects of ADMA. In accordance with medical literature, continuous ADMA infusion caused a decrease in renal perfusion and an increase in reno-vascular resistance at doses that failed to affect BP, renin-angiotensin and sympathetic system [13, 25]. Moreover, it has been shown that ADMA is an independent predictor of progression to the ESRD and death in patients with chronic kidney disease [5, 15, 21]. Indeed, the initial high blood levels of this substance are associated with the future development of adverse cardiovascular events and cardiac death [6]. What is interesting to note, our results might have practical implications, because they suggest that an increase in ADMA levels is a marker of cardiovascular events and in particular is correlated with adrenaline level, having predictive value of mortality among HD patients. For this reason, adrenaline levels might have been used for assessing cardiovascular events in the studied population. Despite the fact that it is not yet clear if it is a progression marker of cardiovascular events. Nevertheless, prospective studies are needed to better elucidate the role of adrenaline in the above observations.

In our study, the majority of patients had hypoalbuminemia. Hypoalbuminemia may be due to albuminuria and/or nutritional deficiency, which may lead to malnutrition, infection and atherosclerosis and predispose to cardiovascular events in chronic kidney disease. Moreover, inflammation in ESRD patients is a multi-factorial problem. Both dialysis-related and dialysis-independent factors may promote inflammation by stimulating the synthesis and/or release of several pro-inflammatory cytokines like CRP, IL-1, IL-6, Tumor Necrosis Factor (TNF- $\alpha$ ); [28]. Circulating levels of CRP were directly and significantly related to ADMA, indicating that inflammation and endothelial dysfunction are parallel processes in ESRD. Thus, event-free survival curves among HD patients indicated $25 \%$ of the deceased in the first 13 months of HD therapy. Given the pathophysiologic links between these factors, these findings suggest that inflammation may lead to expression of inducible NOS. Although various vasoactive factors and cytokines have been shown to have a role in endothelial dysfunction and capillary loss due to reduced production and/or impaired function of NO, they are considered to be the key components that could cause progression of renal injury [17]. In particular, inflammatory reactions in tubulointerstitium, could promote the scarring and fibrotic processes in the damaged kidney. Elevated CRP is another predictor for morbidity and mortality in renal and cardiovascular disease [32]. This acute-phase is widely considered as a marker of underlying inflammatory processes in ESRD [4], and it is associated with carotid artery intima-media thickness [33]. Furthermore, in patients with initially normal intima-media thickness, ADMA and CRP are interacting factors in the progression of carotid intimal lesions [32]. In fact, it has been confirmed that the predictive cardiovascular value of ADMA is similar to that of B-type natriuretic peptide and CRP [20]. This data supports the hypothesis that accumulation of endogenous inhibitor of NOS is an important risk factor for cardiovascular disease in chronic RF and suggests a possible link between ADMA and inflammation [32]. These findings are in line with the results of longitudinal study by our group [32]. 


\section{CONCLUSIONS}

Based on the conducted research, it can be concluded that the concentrations of adrenaline and ADMA level have a predictive value of mortality among HD patients. Of note, lowering plasma ADMA concentration may represent therapeutic target for prevention of progressive renal damage.

\section{REFERENCES}

1. Agarwal R. et al.: Prevalence, treatment, and control of hypertension in chronic hemodialysis patients in the United States. Am. J. Med., $115,291,2003$.

2. Aldámiz-Echevarría L., Andrade F.: Asymmetric dimethylarginine, endothelial dysfunction and renal disease. Int. J. Mol. Sci.,13, 11288, 2012.

3. Alsagaff M.Y. et al.: Asymmetric dimethylarginine: a novel cardiovascular risk factor in end-stage renal disease. J. Int. Med. Res., 40, 340, 2012.

4. Arici M., Walls J.: End-stage renal disease, atherosclerosis, and cardiovascular mortality: is C-reactive protein the missing link? Kidney Int., 59, 407, 2001.

5. Bassareo P.P. et al.: Urinary NGAL and hematic ADMA levels: an early sign of cardio-renal syndrome in young adults born preterm? J. Matern. Fetal Neonatal Med., 26, 80, 2013.

6. Bassareo P.P. et al.: Could ADMA levels in young adults born preterm predict an early endothelial dysfunction? Int. J. Cardiol., 159, 217, 2012.

7. De Jager D.J. et al.: Cardiovascular and noncardiovascular mortality among patients starting dialysis. JAMA, 302, 1782, 2009.

8. Goonasekera C.D. et al.: Nitric oxide synthase inhibitors and hypertension in children and adolescents. J. Hypertens., 15, 901, 1997.

9. Guerin A, Pannier B, London G.: Atherosclerosis versus arterial stiffness in advanced renal failure. Adv. Cardiol.,44, 187, 2007.

10. K/DOQI clinical practice guidelines for chronic kidney disease: evaluation, classification, and stratification. Am. J. Kidney Dis., 39, $1,2002$.

11. Kielstein J.T. et al.: Marked increase of asymmetric dimethylarginine in patients with incipient primary chronic renal disease. J. Am. Soc. Nephrol., 13, 170, 2002.

12. Kielstein J.T. et al.: Asymmetric dimethylarginine plasma concentrations differ in patients with end-stage renal disease: relationship to treatment method and atherosclerotic disease. J. Am. Soc. Nephrol., 10, 594, 1999.

13. Kielstein J.T. et al.: Subpressor dose asymmetric dimethylarginine modulates renal function in humans through nitric oxide synthase inhibition. Kidney Blood Press. Res., 27, 143, 2004.

14. Koch M. et al.: Relevance of conventional cardiovascular risk factors for the prediction of coronary artery disease in diabetic patients on renal replacement therapy. Nephrol. Dial. Transplant., 12, 1187, 1997.
15. Luyckx V.A., Brenner B.M. Low birth weight, nephron number and kidney disease. Kidney Int., 97, 68, 2005.

16. Mallamaci F. et al.: Analysis of the relationship between norepinephrine and asymmetric dimethyl arginine levels among patients with end-stage renal disease. J. Am. Soc. Nephrol., 15, 435, 2004.

17. Nakayama Y. et al.: Asymmetric dimethylarginine accumulates in the kidney during ischemia/reperfusion injury. Kidney Int., 9, 1, 2013.

18. Perticone F. et al.: Endothelial dysfunction, ADMA and insulin resistance in essential hypertension. Int. J. Cardiol., 142, 236, 2010.

19. Raptis V., Kapoulas S., Grekas D.: Role of asymmetrical dimethylarginine in the progression of renal disease. Nephrology (Carlton), $18,11,2013$.

20. Rocha M.S. et al.: Asymmetric dimethylarginine in adults with cystathionine $\beta$-synthase deficiency. Atherosclerosis, 222, 509, 2012.

21. Rodriguez M.M. et al.: Comparative renal histomorphometry: a case study of oligonephropathy of prematurity. Pediatr. Nephrol., 20, 945, 2005.

22. Rutkowski B. et al.: Raport o stanie leczenia nerkozastępczego w Polsce 2009. Drukonsul, Gdańsk 2010.

23. Sarnak M.J., Levey A.S.: Epidemiology, diagnosis, and management of cardiac disease in chronic renal disease. J. Thromb. Thrombolysis, 10, 169, 2000.

24. Schwarz P. et al.: Endogenous and exogenous nitric oxide inhibits norepinephrine release from rat heart sympathetic nerves. Circ. Res., $77,841,1995$

25. Sesti G. et al.: A functional variant of the dimethylarginine dimethylaminohydrolase-2 gene is associated with chronic kidney disease. Atherosclerosis, 231, 141, 2013.

26. Sibal L. et al.: The role of asymmetric dimethylarginine (ADMA) in endothelial dysfunction and cardiovascular disease. Curr. Cardiol. Rev., 6, 82, 2010.

27. Sydow K. et al.: Distribution of asymmetric dimethylarginine among 980 healthy, older adults of different ethnicities. Clin. Chem., 56, $111,2010$.

28. Tripepi G. et al.: Inflammation and asymmetric dimethylarginine for predicting death and cardiovascular events in ESRD patients. Clin. J. Am. Soc. Nephrol., 6, 1714, 2011.

29. U.S. Renal Data System, USRDS 2013 Annual Data Report: Atlas of Chronic Kidney Disease and End-Stage Renal Disease in the United States, National Institutes of Health, National Institute of Diabetes and Digestive and Kidney Diseases, Bethesda, MD, 2013.

30. Ueda S. et al.: Asymmetric dimethylarginine may be a missing link between cardiovascular disease and chronic kidney disease. Nephrology, 12, 582, 2007.

31. Wilcken D.E. et al.: Asymmetric dimethylarginine (ADMA) in vascular, renal and hepatic disease and the regulatory role of l-arginine on its metabolism. Mol. Genet. Metab., 91, 309, 2007.

32. Zoccali C. et al.: Asymmetric dimethylarginine, C-reactive protein, and carotid intima-media thickness in end-stage renal disease. J. Am. Soc. Nephrol., 13, 490, 2002.

33. Zoccali C. et al:. Inflammation is associated with carotid atherosclerosis in dialysis patients. J. Hypertens., 18, 1207, 2000. 